LA-UR- $9 \%-199 \ddot{9}$

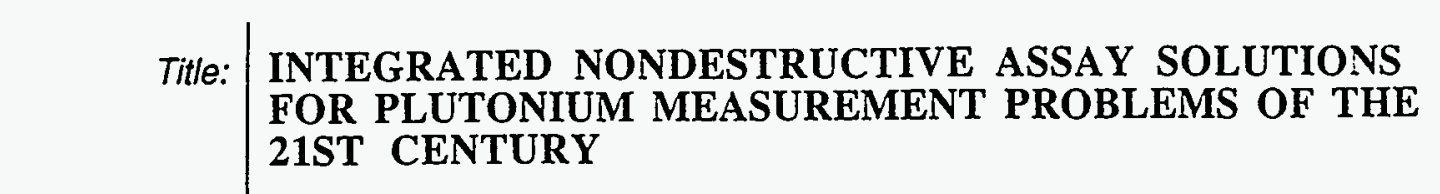

Author(s):

T. E. Sampson and T. L. Cremers

\section{RECEIVED}

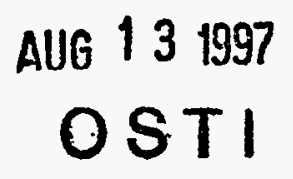

Submitted to:

\section{Los Alamos}

WATIONAL LABOAATOOY

This report was prepared as an account of work sponsored by an agency of the United States Government. Neither the United States Government nor any agency thereof, nor any of their employees, makes any warranty, express or implied, or assumes any legal liability or responsibility for the accuracy, completeness, or usefulness of any information, apparatus, product, or process disclosed, or represents that its use would not infringe privately owned rights. Reference herein to any specific commercial product, process, or service by trade name, trademark, manufacturer, or otherwise does not necessarily constitute or imply its endorsement, recommendation, or favoring by the United States Government or any agency thereof. The views and opinions of authors expressed herein do not necessarily state or reflect those of the United States Government or any agency thereof.
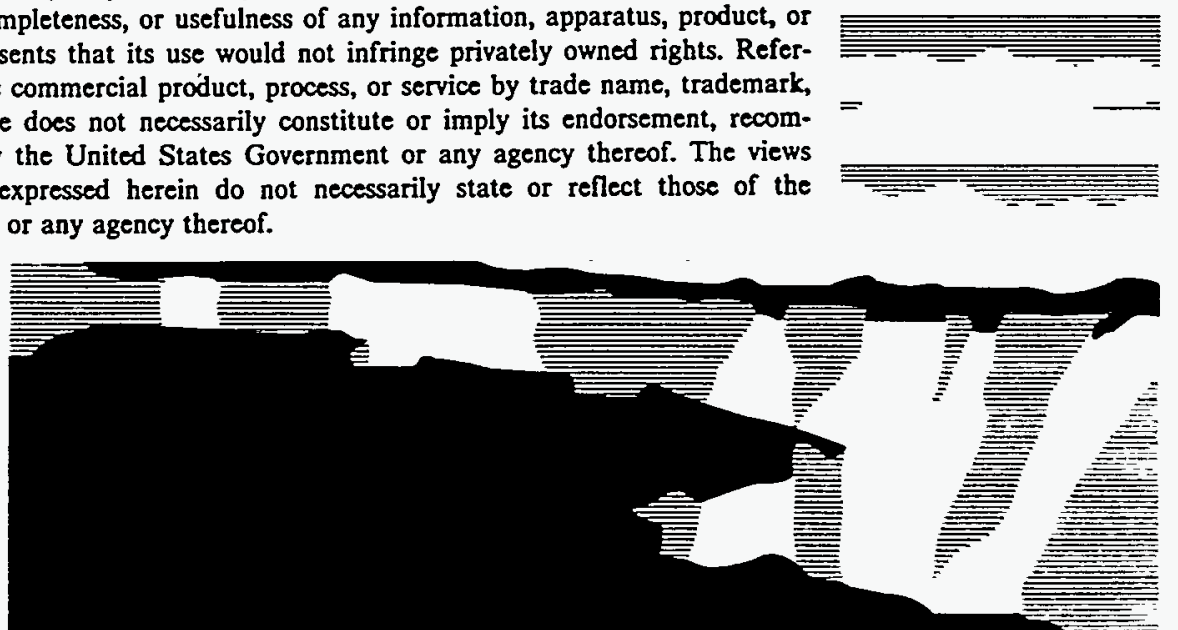

Los Alamos National Laboratory, an affirmative action/equal opportunity emplóyer, is operated by the University of California for the U.S. Department of Energy under contract W-7405-ENG-36. By acceptance of this article, the publisher recognizes that the U.S. Government retans a nonexclusive, royalty-free license to publish or reproduce the published form of this contribution, or to allow others to do so, for U.S. Government purposes. The Los Alamos National Laboratory requests that the publisher identify this article as work performed under the auspices of the U.S. Department of Energy. 


\section{DISCLAIMIER}

Portions of this document may be illegible in electronic image products. Images are produced from the best available original docoment. 


\section{CONTENTS}

\section{ABSTRACT}

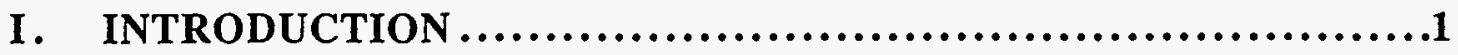

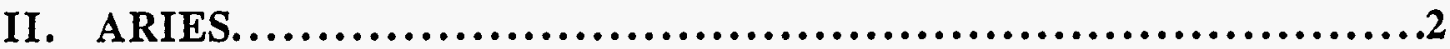

A. The ARIES Process.........................................................

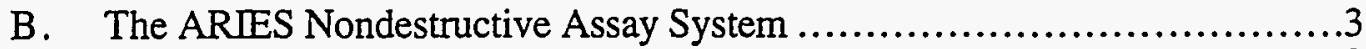

C. Instrument-Measurement Matrix ............................................9

D. Expected ARIES NDA System Performance ................................ 10

E. ARIES NDA System Operation ............................................ 10

F. Other NDA System Features........................................... 11

III. THE LOS ALAMOS NUCLEAR MATERIAL STORAGE FACILITY

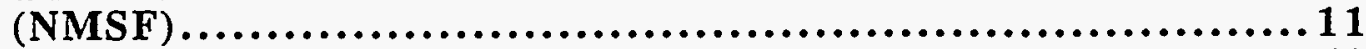

A. Background ....................................................... 11

B. Measurement of 3013 Long-Term Storage Containers ......................11

C. Measurement of Weapons Components in Storage Containers................ 12

IV. OTHER MEASUREMENT SYSTEM APPLICATIONS $\ldots \ldots \ldots \ldots \ldots 13$

A. Residue Stabilization................................................... 13

1. Potential Measurement Problems..................................... 14

2. Application of ARIES NDA System Instruments to 94-1 Residues.......................................................... 16

B. Application of ARIES NDA System Instruments to Materials for Immobilization ............................................. 15

C. Application of ARIES NDA System Instruments to Measurements at the Input of a MOX Facility ............................. 16

D. Inspection of Fissile Materials Excess to US National Security Needs....... 17

E. Other Measurement Problems Associated with Disposition................... 17

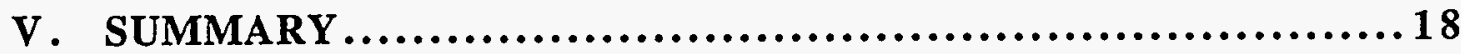

REFERENCES................................................. 19 


\title{
INTEGRATED NONDESTRUCTIVE ASSAY SOLUTIONS FOR PLUTONIUM MEASUREMENT PROBLEMS OF THE 21st CENTURY
}

\author{
Thomas E. Sampson and Teresa L. Cremers \\ Los Alamos National Laboratory \\ Los Alamos, New Mexico 87545 \\ USA
}

\begin{abstract}
We describe automated and integrated NDA systems configured to measure many of the materials that will be found in the DOE complex in the dismantlement, disposition, residue stabilization, immobilization, and MOX fuel programs. These systems are typified by the ARIES (Advanced Recovery and Integrated Extraction System) nondestructive assay system which is under construction at Los Alamos to measure the outputs of a weapon component dismantlement system.
\end{abstract}

\section{INTRODUCTION}

As we approach the 21st century we find ourselves in the midst of great changes in the Department of Energy's programs for the production and utilization of plutonium for national defense purposes. Scientific-Based Stockpile Stewardship and preservation of an extremely limited production capability have replaced large scale weapons production and deterrence by numbers. In the past the primary costs were associated with the building of new weapons; today and in the future the primary costs will be associated with dismantlement, decontamination, residue stabilization, safe and secure storage, and plutonium disposition.

The Safeguards Science and Technology group (NIS-5) in partnership with the Nuclear Materials and Stockpile Management program at Los Alamos is developing, designing, and implementing Nondestructive Assay (NDA) solutions to the Materials Control and Accountability (MC\&A) problems associated with these new missions. These new solutions make extensive use of integration of several different NDA technologies and in most cases use robotics to reduce materials handling, reduce worker radiation exposure, increase throughput, and provide optimum safeguards for the materials. Issues associated with bilateral or international inspection of these materials are also being considered in these new systems.

This report will describe several systems that are under development or being implemented at Los Alamos using this automated and integrated approach and also describes, in less detail, other applications for this technology.

The automated and integrated NDA system for the ARIES (Advanced Recovery and Integrated Extraction System) program will be described in some detail. The ARIES weapons dismantlement program will demonstrate the innovative technologies required for 
the processing of site-returned pits to foundry grade metal in unclassified forms. The ARIES NDA system will go into pilot demonstration in January 1998.

An even more extensive integrated system is being designed for the Nuclear Materials Storage Facility at Los Alamos. Consisting of seven instruments, this system will contain an automated component as for the ARIES system as well as additional instruments for items in larger shipping/storage containers.

We will also describe the straightforward application of these concepts to NDA systems for residue stabilization programs and other programs that may require measurements to be made in a glovebox environment

\section{ARIES}

A. The ARIES Process

ARIES is a program demonstrating weapons component dismantlement and the transformation of the plutonium from classified to unclassified forms. The process produces an output plutonium (metal or oxide) product packaged for long term storage. This product may be used to produce MOX or be destined for ultimate disposition.

The ARIES process consists of the following steps.

Pit bisection Weapons components are introduced to the system and cut apart preparing them for the plutonium removal process.

Consolidation The plutonium is removed from the component by a hydridedehydride or hydride-oxidation process producing an unclassified form of plutonium metal or plutonium oxide.

Canning The resulting product material is canned in a 3013-96 compliant container suitable for long term storage. Plutonium masses in each container are standardized to remove the possibility of identifying the classified plutonium mass in any input item. The standardized plutonium mass is about $4.5 \mathrm{~kg}$.

Decontamination An electrolytic decontamination process is used to remove any contamination from the outer container surfaces.

Nondestructive Assay (NDA) The amount of plutonium in the product containers is assayed with a suite of NDA instruments. The instruments are designed to measure all of the outputs of the process including enriched uranium as well as scrap and waste.

These processes are illustrated in the diagram below. The shaded boxes denote the processes included in the ARIES process pilot demonstration scheduled for cy 1998. 


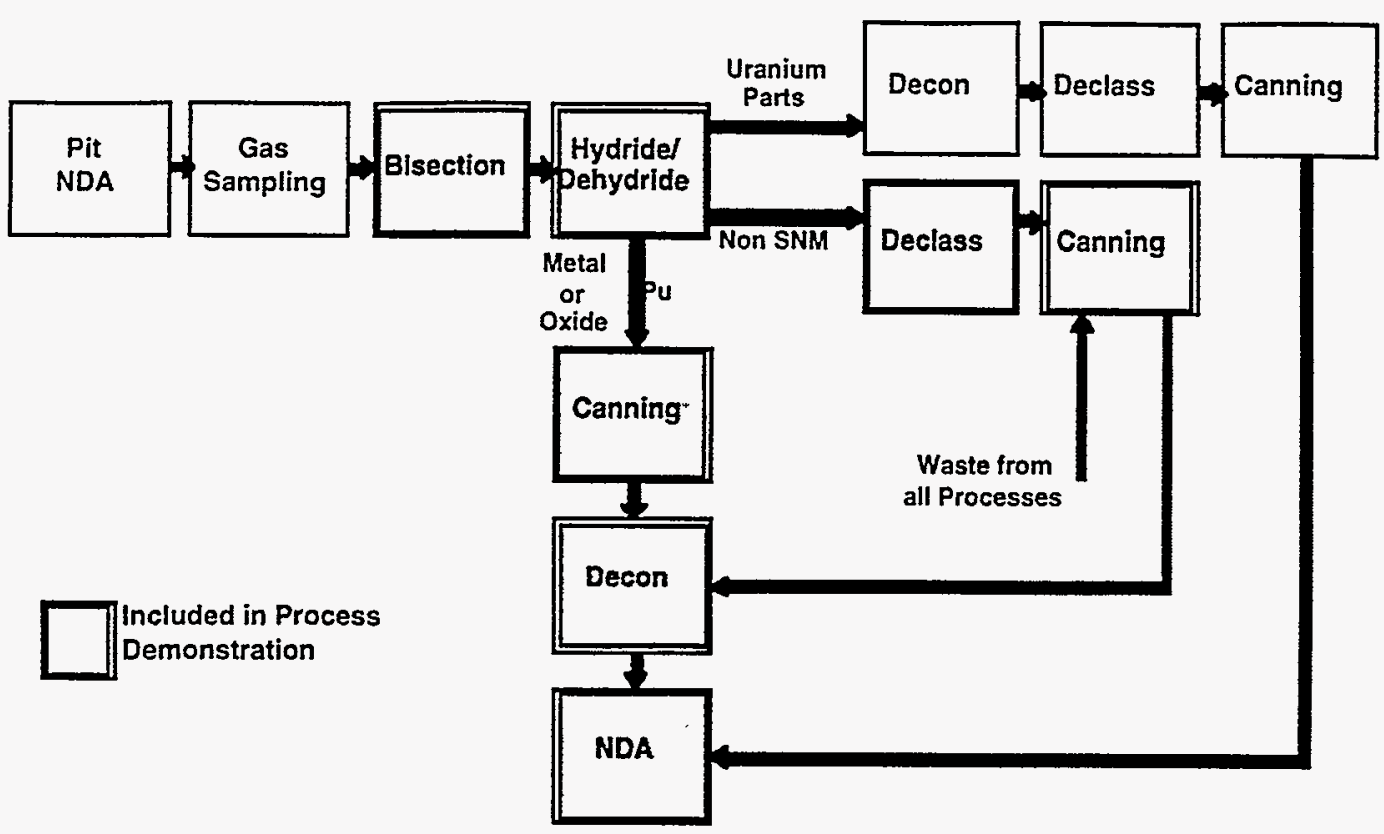

Fig. 1 The ARIES Process

\section{B. The ARIES Nondestructive Assay System}

The ARIES nondestructive assay system consists of four NDA instruments integrated with a central host computer and robotic sample handling. The four NDA instruments are (1) Calorimeter ${ }^{1}$, (2) Gamma spectroscopy of plutonium isotopic composition ${ }^{2}$, (3) Segmented Gamma Scanner (SGS) ${ }^{3}$, and (4) an Active-Passive Neutron Multiplicity counter ${ }^{46}$. Comprehensive information on all of these techniques may also be found in Ref. 7. This suite of instruments is designed to measure all of the outputs of a pit dismantlement operation including both plutonium and enriched uranium. These instruments are all stateof-the-art designs which also have long proven capability in applications worldwide. The Safeguards Science and Technology group at Los Alamos designed and fabricated all of these NDA instruments and also developed all of the software. This integrated approach at a single laboratory greatly facilitates system integration compared with efforts taking software and hardware from different sources.

Calorimeter Measures the heat produced in the radioactive decay of plutonium. Calorimetry is the single most accurate NDA measurement method for bulk materials.

- Water bath, gradient bridge design.

- Seven (7) inch diameter measurement chamber.

- Water bath temperature control to $\pm 0.001{ }^{\circ} \mathrm{C}$.

- WINCAL Windows 3.1-based software.

- Equilibrium measurement with end point prediction or servo control.

- Product measurement time $\sim 4$ hours.

- Wattage range $0.1-20$ watts (a product item is expected to produce about $10-12$ watts of power). 
- Precision

$$
\begin{aligned}
& 0.1 \text { watt } \pm 2 \% \\
& 1.0 \text { watt } \pm 0.25 \% \\
& 10 \text { watts } \pm 0.1 \%
\end{aligned}
$$

Plutonium Isotopic Analysis Analyzes the gamma ray emission and determines the isotopic composition (including americium) of plutonium or uranium. This measurement is used to convert other measurements to elemental masses.

- Los Alamos PC/FRAM isotopic analysis software.

- Product measurement time: $30 \mathrm{~min}-1$ hour.

- $200 \mathrm{~mm}^{2}$ planar HPGe detector or $25 \%$ coaxial HPGe detector.

- Automated count rate optimization.

- Bias for homogeneous items.

$<0.25 \%$ for effective specific power $\left(\mathrm{P}_{\text {eff }}\right)$ (calorimetry)

$<1.0 \%$ for ${ }^{240} \mathrm{Pu}_{\mathrm{eff}}$ (coincidence counting)

- Repeatability (1 RSD).

$-0.3 \%$ for $\left(\mathrm{P}_{\text {eff }}\right)$ in $30 \mathrm{~min}$

$\sim 1.6 \%$ for ${ }^{240} \mathrm{Pu}_{\text {eff }}$ in 1 hour

- Capability for heterogeneous $\mathrm{Am} / \mathrm{Pu}$ analysis.

Segmented Gamma Scanner Quantifies the gamma ray emissions from plutonium or enriched uranium and determines the mass of ${ }^{239} \mathrm{Pu}$ or ${ }^{235} \mathrm{U}$ in low density waste.

- Los Alamos Windows 3.1 software for transmission-corrected passive assay with lump corrections.

- Se-75 transmission source for self absorption corrections.

- Sample container-125mm dia, 3013-compliant double welded SS.

- Able to measure both ${ }^{239} \mathrm{Pu}$ and ${ }^{235} \mathrm{U}$ in low density waste.

- Estimated precision (1RSD) is $1 \%$ for a $50 \mathrm{~g}$ item and a $20 \mathrm{~min}$ measurement.

Neutron Multiplicity Counter Measures coincident neutrons from the spontaneous fission of plutonium or the induced fission of uranium. A versatile instrument that may be used for both product and waste materials.

- Four types of measurements analyzed with Los Alamos NCC software.

Passive

Passive multiplicity

Active (for ${ }^{235} \mathrm{U}$ )

Active/Passive

- Configuration of end plugs changed by robot for different types of measurements.

- Estimated measurement bias for product material $<1 \%$.

- Estimated measurement repeatability for product material $<0.5 \%$ in $30 \mathrm{~min}$.

Two additional critical components of the NDA system are the NDA host computer and the sample-handling robotic system. 
NDA Host Computer An NDA host computer is a central feature of the system. This computer interacts with the individual instrument computers, commands the NDA robot, and sends results to and receives information from the ARIES process control computer.

- $\quad$ Schedule NDA measurements.

- Monitor occupancy sensors, bar code reader.

- Senses and reports status of NDA system.

- Controls NDA robot.

- $\quad$ Combines and archives NDA results.

- Interacts with ARIES process control system.

A block diagram of the ARIES NDA system is shown in Fig. 2.

Robotic Sample Handling The robot has been developed by the robotics group in the Engineering Sciences and Applications division at Los Alamos. It consists of a blend of commercially available components and custom, LANL-designed components.

- Gantry robot with a telescoping $Z$ axis.

- Radiation hardened electronics.

- $\quad$ Round-the-clock operation for increased throughput.

- $\quad$ Reduced worker radiation exposure.

- Reduced human handling of material improves material protection and safeguards.

The ARIES NDA system is laid out in an open-framed gantry structure (Fig. 3) originally intended to mock up a glovebox environment. (You can see the glove ports on the backside of the drawing in Fig. 3.) Other views of the system are shown in Figs. 4 and 5. The success of the ARIES electrolytic decontamination process development meant it was no longer required that the NDA system be installed in a glove box. The mockup "glovebox" that you will see in some of the figures below will be used directly in the ARIES pilot demonstration. An important outgrowth of this is the knowledge that these specific instrument designs are designed to work in a glovebox environment. This technology may be readily adapted to other applications that require a glovebox enclosure and is already being planned for upgrades requiring glovebox operation (not discussed here) at the Los Alamos Plutonium Facility. 


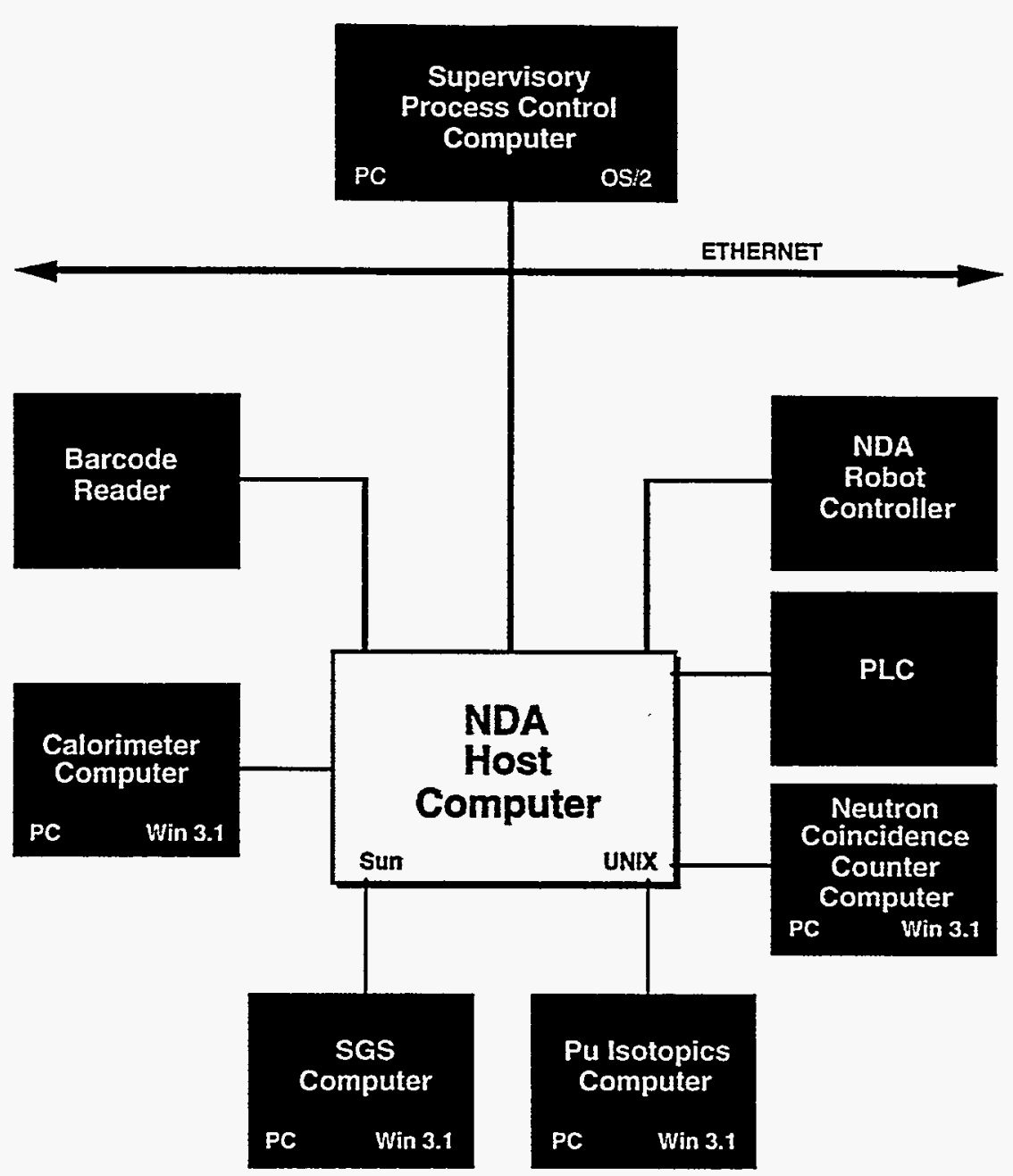

Fig. 2 Block diagram of ARIES NDA system computer communications.

The issue of direct host computer communication with the accountability system deserves mention. This is the subject of other studies and is a much more complicated problem than it appears on the surface. The main problems are not associated with communications. Instead, the main problems involve the selection of data to send to the accountability computer-which data do you use when you have measurements from multiple methods on the same item? This is an area that needs significant new research. 


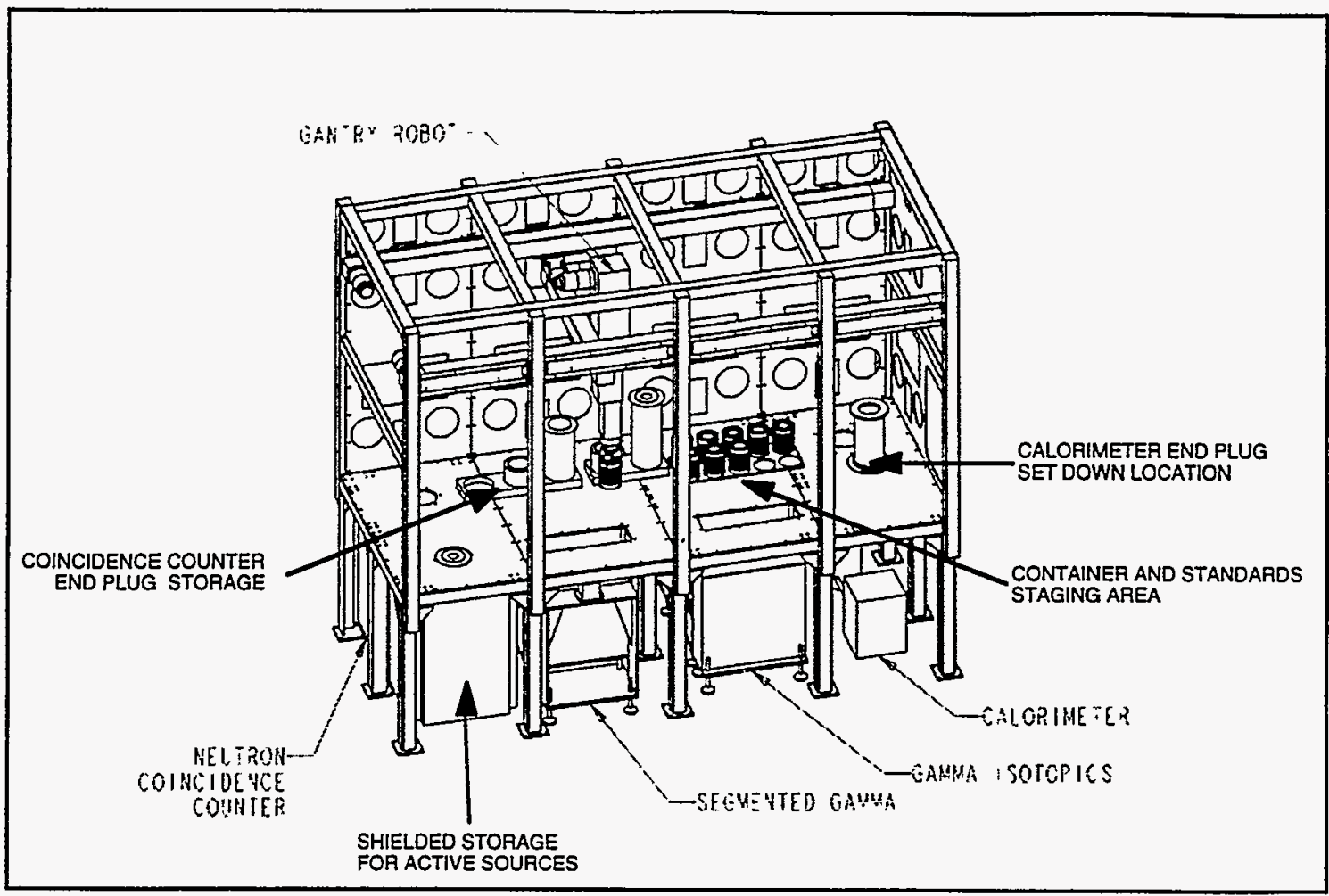

Fig. 3. A sketch of the ARIES NDA system.

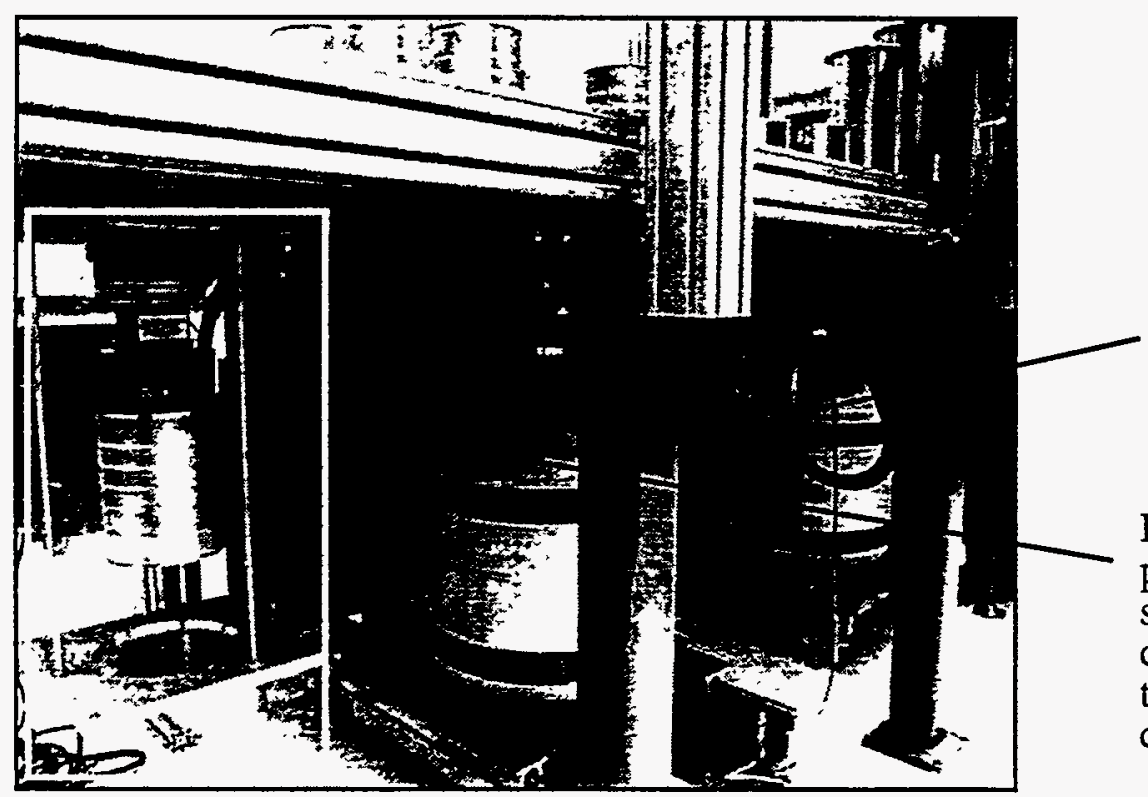

HPGe detector for the SGS

HPGe detector for the plutonium isotopic analysis system. Detector position is controlled by stepping motors to allow optimization of the counting rate.

Position of calorimeter shown before its installation.

Fig. 4. Gamma ray measurement systems underneath the ARIES NDA gantry structure. 


\section{DRAFT}

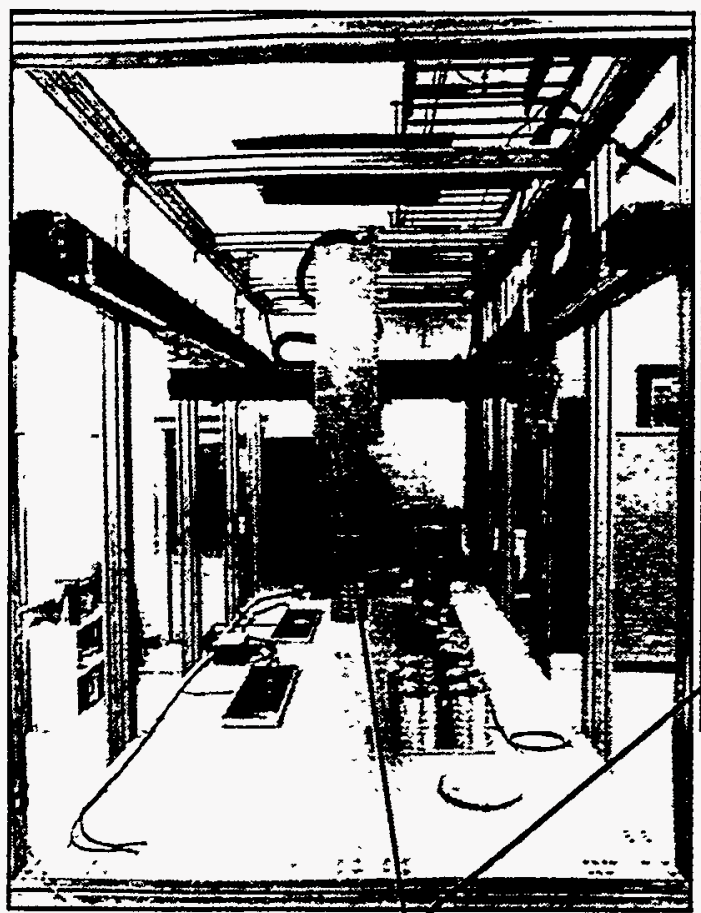

Robot telescoping $\mathrm{Z}$ axis
DRAFT

DRAFT

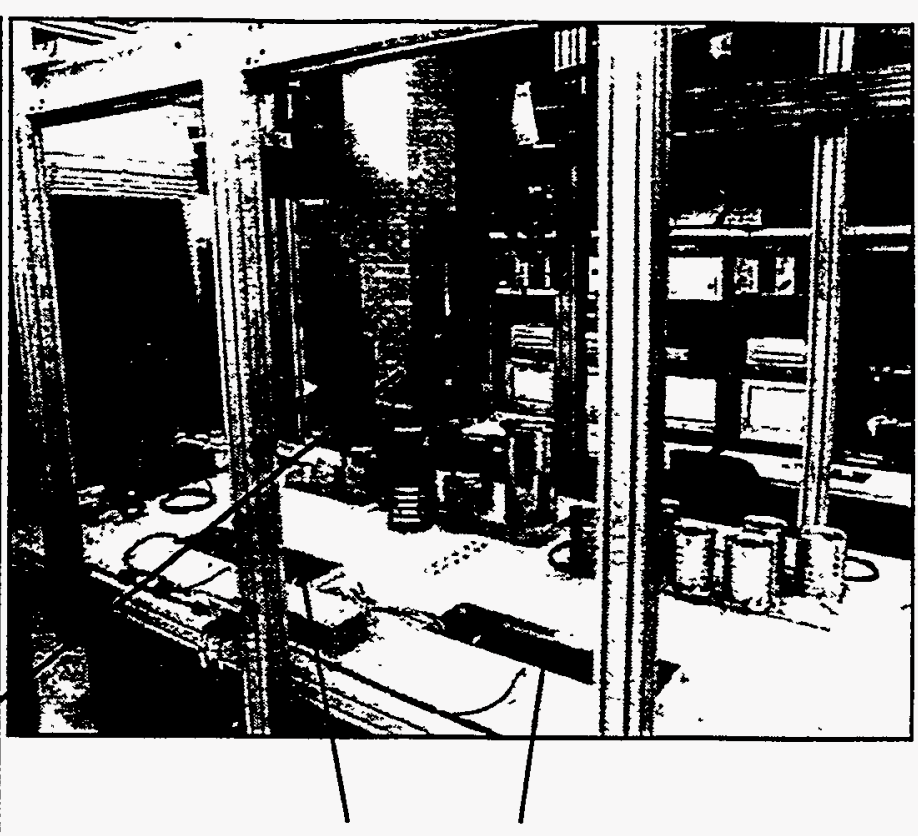

SGS and Pu isotopics sample wells

Fig. 5. Two views of the ARIES NDA system gantry robot structure.

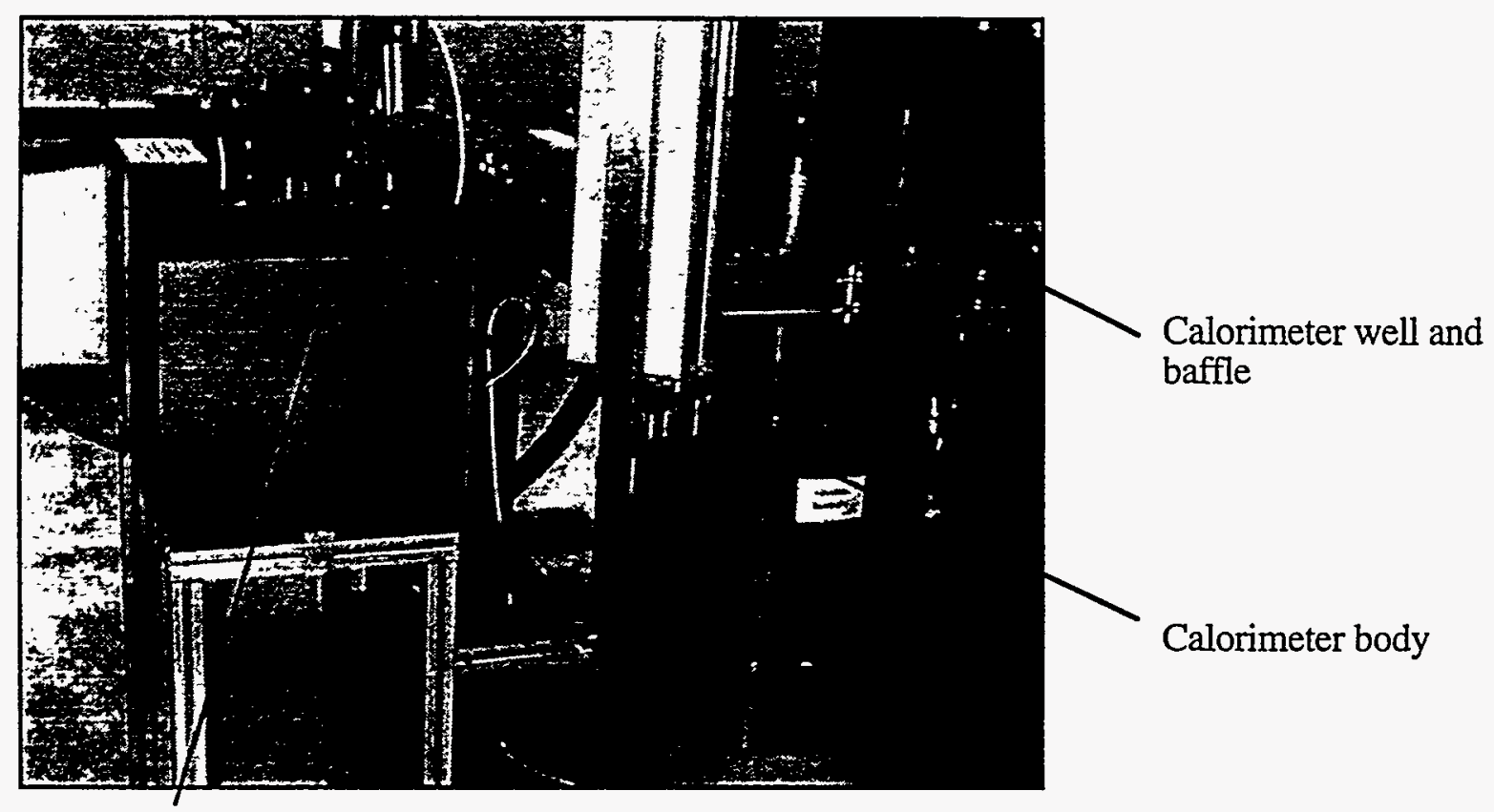

Calorimeter water bath temperature controller

Fig. 6. The ARIES calorimeter and its water bath temperature controller. 


\section{Instrument-Measurement Matrix}

The matrix shown below (Table I) was developed to guide the instrument selection given the types of items expected from the ARIES process. As the ARIES program progresses into its pilot demonstration phase, all measurement methods will be thoroughly evaluated on actual process materials. For example, we will study the applicability of the coincidence counter versus the SGS for various low density waste forms. The outcome of these studies may lead to a slightly different instrument mix for later ARIES systems.

The flexibility of the current instrument mix is indicated by considering that changes that have been made in the process parameters have not required any changes in NDA instrument mix or instrument design.

Table I. Instrument-Measurement Matrix for ARIES NDA system.

\begin{tabular}{|c|c|c|c|c|c|}
\hline \multirow[b]{2}{*}{ Item Measured } & \multirow{2}{*}{$\begin{array}{c}\text { Amount } \\
\text { SNM }\end{array}$} & \multicolumn{4}{|c|}{ Measurement Method } \\
\hline & & SGS & Calorimeter & $\mathrm{Pu}$ Isotopic & Coincidence $\mathrm{Ctr}$ \\
\hline Pu Metal Product & $>100 \mathrm{~g}$ & & $\mathrm{x}$ & $\mathrm{x}$ & Possible \\
\hline Pu Oxide Product & $>100 \mathrm{~g}$ & & $x$ & $\mathrm{x}$ & Possible \\
\hline Bisection Waste (lathe) & $<10 \mathrm{~g}$ & $\mathrm{x}$ & & Possible & Possible \\
\hline $\begin{array}{l}\text { Pu-Contaminated } \\
\text { High Density Waste }\end{array}$ & $<50 \mathrm{~g}$ & & & $\mathrm{x}$ & $\mathrm{x}$ \\
\hline $\begin{array}{l}\text { Pu-Contaminated } \\
\text { Low Density Waste }\end{array}$ & $<50 \mathrm{~g}$ & $\mathrm{x}$ & & Possible & Possible \\
\hline Enriched Uranium & $>500 \mathrm{~g}$ & & & $* *$ & Active \\
\hline Depleted Uranium & $>500 \mathrm{~g}$ & & & $* *$ & Passive \\
\hline $\begin{array}{l}\text { Enriched U Contaminated } \\
\text { Low Density Waste }\end{array}$ & $<50 \mathrm{~g}$ & $\mathbf{x}$ & & $* *$ & \\
\hline $\begin{array}{l}\text { Depleted U Contaminated } \\
\text { Low Density Waste }\end{array}$ & & \multicolumn{4}{|c|}{ No good assay method with this system } \\
\hline
\end{tabular}

** Measurement possible with coaxial HPGe detector. Current demonstration system uses planar HPGe.

The instruments chosen for ARIES possess additional measurement capabilities not required for the initial ARIES pilot demonstration. An americium removal (Molten Salt Extraction, for example) step could be included in the ARIES system and the above instrument mix could still measure the heterogeneous $\mathrm{Am} / \mathrm{Pu}$ residues produced in that process. The same instrument mix could also measure the outputs and wastes from a MOX production line-an important consideration now that MOX has been chosen as one of the disposition options. 


\section{Expected ARIES NDA System Performance}

Historical performance of instruments of the type represented in the ARIES NDA system can be used to predict the performance of the system. We have examined the data from the USDOE Calorimetry Exchange for Los Alamos systems with the same type of calorimeter and gamma ray isotopic analysis represented in the ARIES NDA system. Combining the precision and the bias in quadrature for both calorimetry and gamma isotopics gives a total uncertainty of $<0.5 \%$ ( 1 RSD). We expect ARIES to perform in a similar manner when combining calorimetry and gamma ray isotopic analysis on product material.

Neutron_coincidence_counting_can_also_be_combined_with isotopic_analysis_to_give results for total plutonium for product materials. Our best estimates yield an expected total uncertainty of between $1.5 \%$ and $2.5 \%$ for this combination.

Uncertainty estimates for low density waste measurements using the SGS or the coincidence counter are very much sample dependent and difficult to predict. Here, total uncertainties of $10 \%$ or less are acceptable and thought possible with either system. Any high density waste with mass $<\sim 50$ grams may be measured in the coincidence counter also with an uncertainty estimated to be under $10 \%$.

\section{E. ARIES NDA System Operation}

An NDA measurement begins with the presentation of the NDA item at the input station of the system. This presentation is presently a manual operation but planned upgrades will allow a robot to place the item into the input station. The presence of an item in the input station is sensed by a fiber optic occupancy sensor and made known to the NDA host computer. The host computer instructs the robot's barcode reader to read the data matrix barcode on the top of the container and to transport the can to the shielded storage array for the containers. Information in this barcode tells the system the material type inside the container allowing the host computer to schedule the appropriate measurements. Items may be measured in more than one instrument. Most items will be measured at least twice with the isotopic composition measurement performed on nearly all items. The shielded storage array allows for staging of six items awaiting measurement and permanent storage for four measurement control/calibration standards.

When the scheduled instrument is available, the host computer instructs the robot to move the item from the storage array to the instrument. The host computer then instructs the NDA instrument computer to begin the measurement. At the completion of the measurement the NDA instrument computer transmits the measurement results to the host computer where they are stored in a database. The host computer directs the robot to move the measured item from the NDA instrument back to its position in the storage array where it awaits scheduling for any additional measurements. After completion of all required measurements the robot moves the item from the storage array to the output station where it is manually removed from the system. After completion of the required measurements the host computer combines the NDA measurement results to produce a measured value for the elemental plutonium mass. The NDA results may be printed at the host computer and are archived for transmittal to the process control computer. Although not a step in the initial ARIES demonstration, it would be straightforward to transmit the measurement results to an accountability system. 


\section{F. Other NDA System Features}

Every location potentially containing an item or instrument end plug is instrumented with a fiber optic occupancy sensor. The status of these sensors is read by the NDA host computer and displayed on a panel on the instrument console. Monitoring these sensors allows the host to assess the status of the measurement system at all times.

Several safety features are associated with the robot. A light curtain around the periphery of the gantry frame shuts down robot operations when it senses any intrusion into the robot's working space. The robot gripper contains a force sensor which shuts off the robot if the robot encounters an obstacle. The force sensor also provides an approximate weight for each container. This weight may be used for verification purposes and also for criticality safety assurance.

The storage array is heavily shielded on four sides and the bottom to reduce radiation exposure to those in the vicinity and to reduce radiation background in the assay instruments. The shielding consists of $10 \mathrm{~cm}$ of polyethylene encased in $0.75 \mathrm{~mm}$ of stainless steel. An additional $12.7 \mathrm{~mm}$ of tungsten shielding is placed underneath the polyethylene shielding.

\section{THE LOS ALAMOS NUCLEAR MATERIAL STORAGE FACILITY (NMSF) \\ A. Background}

The Los Alamos National Laboratory is redesigning and rebuilding its Nuclear Material Storage Facility to better adapt to the changing requirements for safe, secure storage of plutonium. A count room incorporating a full suite of NDA instruments is a part of the facility. This section will describe the NDA systems planned for this new facility which is scheduled to go into service in 2002.

The NMSF is designed to handle two types of containers. The first container type is the standard DOE-approved container for long term storage as specified by the $3013-96^{8}$ standard. The vast majority of the material stored in the NMSF will use these containers. The other container will be a larger container designed for storage of weapons components (pits) as Los Alamos continues its active role in stockpile surveillance as well as assuming a limited stockpile maintenance capability. We have specified instruments designed to measure all of the materials housed in either container.

\section{B. Measurement of 3013 Long-Term Storage Containers}

The DOE 3013 standard specifies functional requirements and overall size for long term storage containers. Of particular interest for $\mathrm{NDA}$ is the requirement that the containers have an SNM concentration of at least 50\%. This means that a full container should have an SNM content of over $2 \mathrm{~kg}$. Another requirement that eases the problems associated with the standardization and sizing of the NDA equipment is the required diameter of $125 \mathrm{~mm}$. These requirements are completely compatible with what we will call an "ARIES-like" NDA system.

These requirements suggest an ARIES-like NDA system incorporating a second calorimeter replacing the SGS. The high density of a maximum loading $(5 \mathrm{~kg})$ of $\mathrm{PuO}_{2}$ makes SGS measurements difficult and the second calorimeter will provide an accuracy 20 - 
50 times better than an SGS. We will not have low density waste to measure--the forte of the SGS.

The proposed suite of instruments to measure 3013 long-term storage containers consists of

- Two (2) calorimeters.

- One gamma ray isotopic analysis system.

- One active/passive neutron multiplicity counter.

- System integration with host computer

The instruments for an automated system of this nature can be contained in a floor area of less than $100 \mathrm{ft}^{2}$ (excluding instrumentation racks). The available floor space in the NMSF will probably allow an expansion of the area allocated to this instrument suite. A larger floor area will allow more shielding around the instruments as well as increased shielding around the staging area for the items to be measured but will increase the size and cost of the robotics. The layout of this component of the NMSF system will be tailored to the facility requirements.

\section{Measurement of Weapons Components in Storage Containers}

The containers used to store weapons components (pits) are much larger than those used for the other materials in the facility. The instrumentation requirements are also somewhat different given the unique nature of the contained materials. We propose a suite of three instruments sized for this special task with the ability to measure the weapons pits and also serve as a backup for the instruments measuring the 3013 container contents. These instruments will be

- Calorimeter, sized for pit storage containers.

- Gamma-ray isotopic analysis system.

- Californium shuffler ${ }^{2}$ with multiplicity counting capability sized for 200 liter drums to also serve as backup for the shuffler in the Los Alamos Plutonium Facility.

These instruments are expected to have fairly low throughputs and are not felt to require a full robotic system. Instead, we propose to incorporate fixed automation to assist the manual handling of the large pit storage containers.

The two suites of instruments in the NMSF and the existing instruments in the Los Alamos Plutonium Facility Count Room (PF4 NDA) will back up each other as outlined in the figure below. 


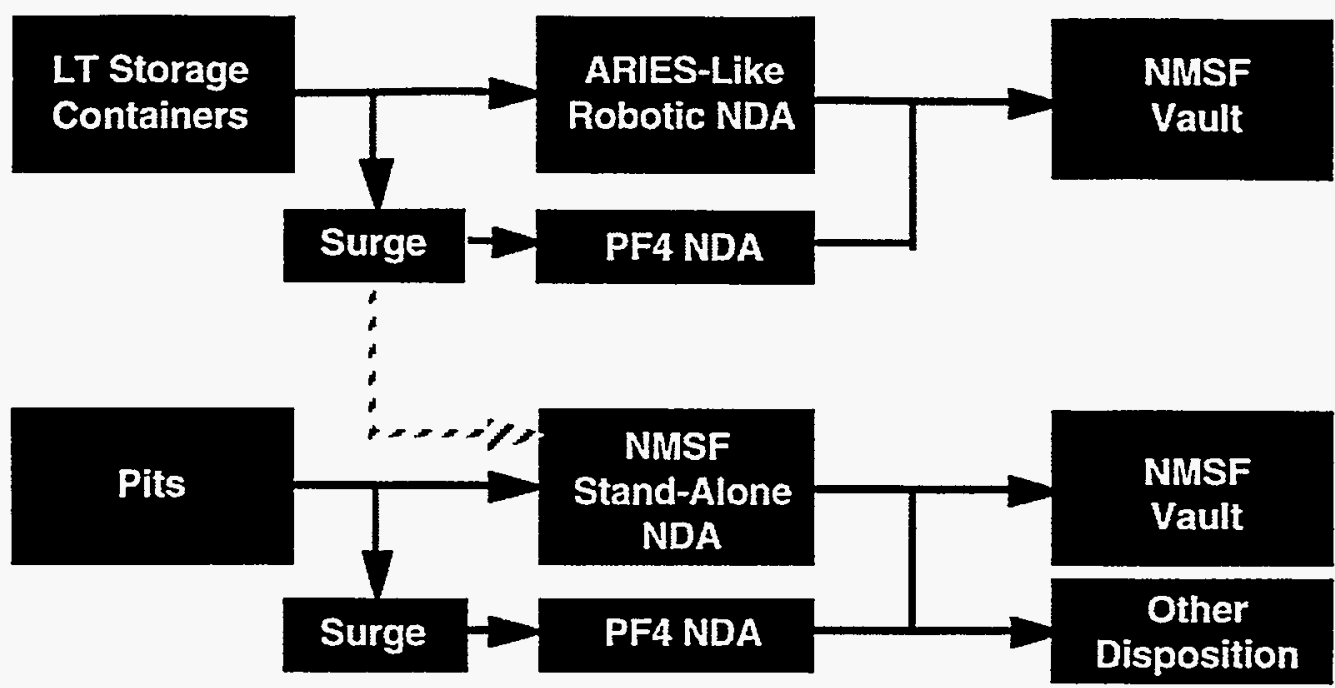

Fig. 6. Nuclear Material Storage Facility Count Room NDA and interactions with PF4 Count Room.

The issue of host computer control is being studied for the three standalone instruments for the pit containers. Options are 1) standalone instruments with no host computer as in the PF4 NDA lab, 2) separate host computer for the three instruments, and 3) integrate with the host computer for the "ARIES-like" system measuring the 3013 containers. This selection will be made during the Title I conceptual design phase now underway.

\section{OTHER MEASUREMENT SYSTEM APPLICATIONS}

Other applications of automated and integrated nondestructive assay systems arise in the Department of Energy programs for residue stabilization and in several aspects of the disposition program for plutonium.

\section{A. Residue Stabilization}

In 1994 the Defense Nuclear Safety Board (DFNSB) issued an order (94-1) requiring that wastes from plutonium processing that were in storage be stabilized and repackaged in a form suitable for long term storage. These requirements were issued to increase the safety of the plutonium residue inventory as unstable residues and corroding containers were becoming a serious safety problem for the Department of Energy. The 3013 long term storage container standard originated from the 94-1 requirements.

This program presents some challenges for nondestructive assay as the stabilized materials are likely to be highly impure. The 3013 storage standard requires at least $50 \%$ SNM content alleviating the problem somewhat for these high equity residues. However, 
the lower concentration residues, likely slated for disposition by immobilization, will present the biggest problems for NDA.

1. Potential Measurement Problems. Impure residues present measurement problems in several areas. Below we list known problems and suggest how to handle them in an ARIES-like NDA system.

Low $Z$ Impurities Low $Z$ impurities $(<Z \sim 20)$ in plutonium-bearing materials serve as targets for the alpha particles emitted from the plutonium and americium isotopes. They cause an (alpha, $\mathrm{n}$ ) reaction producing a single neutron. One example is the reaction

$$
\alpha+{ }^{18} \mathrm{O} \rightarrow{ }^{21} \mathrm{Ne}+\mathrm{n}
$$

The (alpha, $\mathrm{n}$ ) neutrons complicate neutron coincidence measurements by causing high singles detection rates and also by causing induced fission in the SNM present. In many cases these problems may be surmounted by adopting the technique of neutron multiplicity counting allowing correction for these effects for cases where the (alpha, n) neutron production rate does not greatly exceed the natural spontaneous fission rate from the item. The neutron multiplicity counting technique is a major feature of the ARIES NDA system. The Los Alamos NCC software ${ }^{10}$ has capability to analyze measurements exhibiting a wide range of (alpha, $n$ ) contributions.

The calorimeter that is a principal component of the ARIES system is unaffected by low $\mathrm{Z}$ impurities giving assurance that the calorimetry technique will always work for items containing low $\mathrm{Z}$ impurities, given that the calorimeter's operating mass range is appropriate for the item contents. The potential penalty is that of measurement time. A high throughput system will require multiple calorimeters.

Isotopic analysis by gamma ray spectrometry is unaffected by low $\mathrm{Z}$ impurities.

Additional Radionuclides Many of the residues are expected to exhibit high concentrations of radionuclides, other than plutonium or uranium. Isotopes such as ${ }^{237} \mathrm{~Np}$, ${ }^{243} \mathrm{Am}-{ }^{239} \mathrm{~Np},{ }^{244} \mathrm{Cm}$ and to a lesser extent ${ }^{242} \mathrm{Cm}$, may be present. The most common radioisotope expected is ${ }^{241} \mathrm{Am}$. While this isotope is always a constituent of pure plutonium (arising from the decay of ${ }^{241} \mathrm{Pu}$ ), it is often found highly concentrated in the residues from plutonium purification and separation operations. These residues may contain many 10 s of percents or more ${ }^{241} \mathrm{Am}$ by weight with some residues being nearly completely americium.

Both curium isotopes exhibit high spontaneous fission rates which will interfere with neutron coincidence counting measurements, including neutron multiplicity counting. The other isotopes, especially ${ }^{241}$ Am will contribute to the (alpha, $n$ ) neutron rate from the item. Current neutron multiplicity counting techniques are extremely imprecise for $\alpha>10$ where $\alpha$ is defined as the ratio [(alpha, $\mathrm{n}$ ) neutron rate/spontaneous fission neutron rate].

The additional radionuclides can be identified and usually quantified relative to plutonium by the isotopic analysis system. In some pathological cases where the additional radionuclides overwhelm the plutonium, it may not be possible to obtain a plutonium isotopic distribution. 
Calorimetry will sense the heat production from the additional radionuclides. If these nuclides can be quantified with respect to plutonium by the gamma spectroscopy measurement, the calorimetry measurement will be successful although possibly degraded in precision (resulting from a difficult gamma ray isotopic measurement). When the gamma ray signals from the additional radionuclides overwhelm those from the plutonium, it may not be possible to use the gamma ray measurement to interpret the calorimetry data. High concentrations of ${ }^{237} \mathrm{~Np}$ relative to plutonium are expected to be an example of this situation.

Isotopic Heterogeneities Two types of items can exhibit isotopic heterogeneities.

The first type of heterogeneity occurs when plutonium residues from batches with different isotopic compositions are placed in the same container without thorough mixing and blending. The isotopic analysis measurement is most affected in this case. The isotopic results will be bounded by the limits of the individual isotopic distributions but will not represent a proper weighted average.

The second type of heterogeneity occurs when plutonium and americium reside in different matrices within the same item. The classic example here is the residue from a molten salt extraction americium separation process. Here the americium that is removed from the plutonium undergoing purification appears in the residue as a salt, $\mathrm{AmCl}_{2} / \mathrm{AmCl}_{3}$. Small amounts of plutonium as plutonium metal fines are also present the salt matrix.

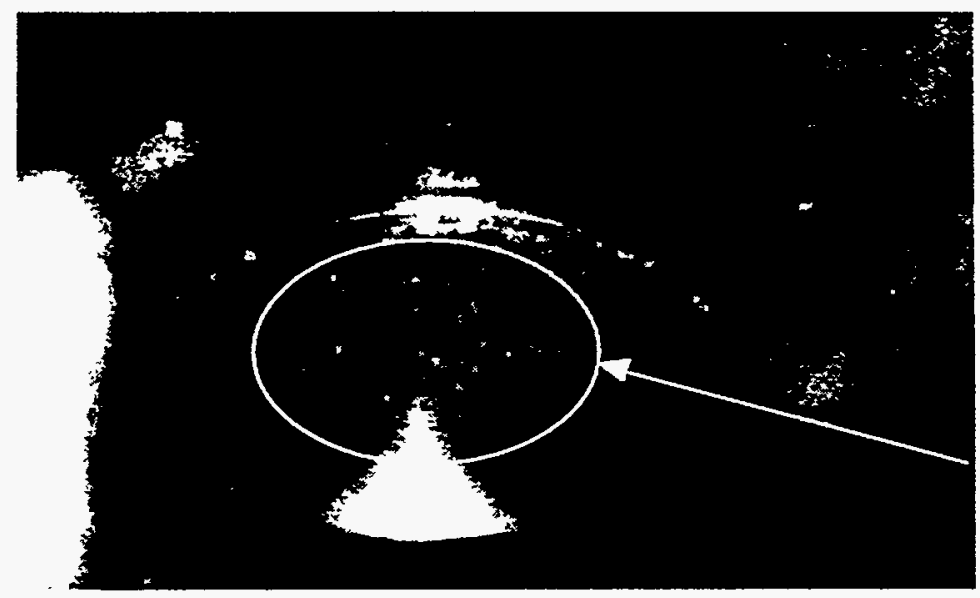

Fig. 7. Plutonium metal fines sieved from $a$ crushed and blended MSE salt.

Because the americium and the plutonium reside in different matrices, their gamma rays suffer different attenuation for the same energy. The relative detection efficiencies are different for the two isotopes because the two isotopes have different spatial distributions. The Los Alamos PC/FRAM ${ }^{11,12}$ isotopic analysis software allows for this effect enabling the isotopic analysis to yield correct $\mathrm{Am} / \mathrm{Pu}$ ratios necessary for interpretation of calorimetry measurements.

The measurement of the heat output in a calorimeter is unaffected by isotopic heterogeneities. It is only the measurement of the isotopic composition and ${ }^{241} \mathrm{Am}$ content that presents possible problems, as discussed in the previous paragraph.

Neutron coincidence counting is also unaffected, in principle, by isotopic heterogeneities. In the first case mentioned above, that of an incomplete mixture of two different isotopic distributions, we do not expect an effect. In the second case, the $\mathrm{Am} / \mathrm{Pu}$ 
heterogeneities, the effect arises, not from the heterogeneity, but from the high americium content usually found in residues of this type. If the americium content is too large, its high alpha activity will increase the (alpha, $\mathrm{n}$ ) neutron rate from the low $\mathrm{Z}$ constituents of the item. This may increase $\alpha$ such that coincidence counting measurements fail.

2. Application of ARIES NDA System Instruments to 94-1 Residues. In spite of the residue measurement problems cited above, it would appear that an instrument suite consisting of calorimetry, gamma ray isotopic analysis, and neutron multiplicity counting is nearly optimum for residue measurements in 3013 containers or other containers with similar dimensions. There would appear to be few problems that this suite could not handle, although accuracy and precision, relative to values for product materials, will be degraded for many of the residues.

\section{B. Application of ARIES NDA System Instruments to Materials for Immobilization}

Studies ${ }^{13,14}$ to date suggest an immobilization concept of small cans containing plutonium at $<10 \%$ by weight in a borasilicate glass or ceramic matrix without added high level waste (HLW) or fission products. The plutonium content is proposed to be about 2.5 $\mathrm{kg} / \mathrm{can}$. These cans would then be loaded into a larger glass $\log (0.6 \mathrm{~m}$ dia. by $3 \mathrm{~m}$ tall) containing HLW to provide a radiation barrier equivalent to the "spent fuel standard."

The individual small cans (depending upon their exact size) also appear to be able to be analyzed with an ARIES-like NDA system, again with calorimetry, neutron multiplicity counting, and gamma ray isotopic analysis. An absorbing matrix as represented by borasilicate glass could present some challenges to the neutron measurements and the effects of the higher density glass or ceramic on the gamma isotopics also needs study.

Accurate NDA measurement of each small can before placement in the canister should preclude the much more difficult and expensive measurement of the entire glass log with its HLW inventory.

\section{Application of ARIES NDA System Instruments to Measurements at the Input of a MOX Facility.}

As with any other major nuclear processing facility, the MOX facility envisioned in the disposition program will require a variety of specially designed and configured NDA instruments. The Safeguards Science and Technology group at Los Alamos, during the past 15 years, has built many such special purpose instruments for use in Japanese and European MOX facilities. Descriptions of some of the instruments and concepts may be found in Ref. 15-17.

The ARIES NDA suite (without the SGS) is ideally suited to measure the input plutonium cans as well as the input uranium oxide assuming packaging in a container similar to the 3013 container. The plutonium oxide would be measured as shown in Table I while the uranium oxide would be measured by the active neutron portion of the coincidence counter. Isotopic measurements could be performed on both materials. 


\section{Inspection of Fissile Materials Excess to US National Security Needs}

The materials from an ARIES weapons dismantlement process and high purity stabilized 94-1 residues may be offered for international inspection as excess fissile materials. Specifically, in September 1993, and in March 1995, President Clinton announced that the U.S. would place excess fissile material no longer needed for our defense needs under IAEA safeguards to show the irreversibility of the nuclear dismantlement process. The AIRES production facility is being designed to incorporate the requirements of IAEA inspection of these materials.

The types of instruments and measurements represented in the ARIES NDA are very familiar to the IAEA. Neutron coincidence counting has been a mainstay of IAEA inspection techniques for many years. Most recently, Los Alamos has assisted the IAEA in applying neutron multiplicity counting techniques to the measurement of impure plutonium oxide at Rocky Flats and Hanford for verification of US excess fissile materials. ${ }^{18.19}$ The neutron multiplicity counting method, a principle instrument in the ARIES NDA suite, is now also an accepted measurement method for the IAEA.

Plutonium gamma ray isotopic analysis measurements are also regularly used by the IAEA in conjunction with neutron coincidence counting. The PC/FRAM isotopic analysis software in the ARIES system has been accepted for use by the IAEA for measurement of excess weapons plutonium at Rocky Flats.

Calorimetry has never been routinely used by the IAEA because its measurement times are usually not compatible with inspection requirements. Also, the US is the only country extensively using calorimetry and, until recently, there were no IAEA inspections of plutonium in the US. However, the IAEA inspections at Rocky Flats and Hanford have pointed out a role for calorimetry. It can be used as a referee measurement and it can also provide bias defect level measurements (the highest level of IAEA verification) obviating the need for sampling, shipment of samples to Vienna, and destructive analysis. Calorimetry is now becoming a very cost effective option for some types of IAEA measurements. The IAEA is in the process of certifying calorimetry for use in the inspection of US excess fissile materials.

Because the measurement methods and the specific software used in the ARIES NDA suite are compatible with IAEA measurement methods and requirements, the US and the IAEA are beginning to discuss how an ARIES weapons dismantlement NDA system or an ARIES-like system may be jointly used by the US facility and the IAEA. Joint use requires authentication of the data, unattended operation, and possible remote monitoring. These concepts are well studied although their implementation is usually unique to each facility. Los Alamos has extensive experience in fielding unattended instruments for IAEA use. As of April 1997 Los Alamos instruments had logged over 300 system-years of unattended operation in support of IAEA safeguards requirements.

\section{E. Other Measurement Problems Associated with Disposition}

The ARIES NDA system does not address all of the NDA problems associated with the dismantlement and disposition programs. Indeed, the low level and TRU wastes produced throughout these processes are best measured with techniques optimized for 200 liter (or larger) drums. Here calorimetry, as currently practiced, is not an option because of the size of the containers relative to the low plutonium masses contained. 
Isotopic analysis can still be used as can the methods of passive and active neutron coincidence counting. The emerging technology of Tomographic Gamma Scanning (as a successor to the SGS) is ideally suited for measurement of many of these often highly heterogeneous waste drums.

The technologies used in these applications have been most recently described in Ref. 20.

\section{SUMMARY}

We have described the automated and integrated NDA systems that are being developed at the Los Alamos National Laboratory for application to safeguards problems arising in weapons dismantlement, residue stabilization, and plutonium disposition programs.

Automated NDA systems using a suite of instruments containing calorimetry, gamma spectrometry measurement of plutonium isotopic composition, active and passive neutron coincidence/multiplicity counting, and in some instances, segmented gamma scanning can measure most all of the materials expected to be packaged in containers meeting the DOE 3013-96 long term storage standard. When these systems are automated with robotic handling of the containers the user gains the benefits of increased throughput, reduced radiation exposure, and improved material control.

The first Los Alamos system of this type is being constructed for the ARIES weapons dismantlement program. This NDA system is planned for operation in the ARIES pilot demonstration program in January 1998.

This type of system may also be applied, largely unchanged from its ARIES configuration, to similar problems arising in residue stabilization, disposition by immobilization, and MOX fuel fabrication - the principal DOE activities in the 21st century.

The instruments in this NDA suite are compatible with IAEA measurement methods and thus may be used, with proper authentication, in a dual use mode in facilities undergoing IAEA inspection. 


\section{REFERENCES}

1. Plutonium-Bearing Solids-Calibration Techniques for Calorimetric Assay, American National Standard, ANSI N15.22-1987, American National Standards Institute, Inc, New York, New York, January 1987.

2. FRAM Plutonium Isotopic Analysis System, Los Alamos National Laboratory Application Note, LALP 93-86, November 1993.

3. Segmented Gamma-Ray Scanner, Los Alamos National Laboratory Application Note, LALP 91-011, March 1991.

4. Passive Neutron Coincidence Counters, Los Alamos National Laboratory Application Note, LALP-92-52, December 1992.

5. Passive/Active Neutron Coincidence Counter, Los Alamos National Laboratory Application Note, LALP-93-31, April 1993.

6. Passive Neutron Multiplicity Counter, Los Alamos National Laboratory Application Note, LALP-94-44, June 1994.

7. Doug Reilly, Norbert Ensslin, and Hastings Smith, Jr., Passive Nondestructive Assay of Nuclear Materials, NUREG/CR-5550, 1990.

8. Criteria for Preparing and Packaging Plutonium Metals and Oxides for Long-Term Storage. DOE-STD-3013-96, U.S. Department of Energy, Washington, DC 20585, September 1996.

9. The 252 Californium Shuffler, Los Alamos National Laboratory Application Note, LALP-90-15, March 1990.

10. W. C. Harker, M. Krick, "Neutron Coincidence Counting Software for Windows," Proceedings of the Institute of Nuclear Materials Management, 37th Annual Meeting, Naples, Florida, July 28-August 1, 1996.

11. Thomas A. Kelley, Thomas E. Sampson, and Dorothea DeLapp, "PC/FRAM: Algorithms for the Gamma-ray Spectrometry Measurement of Plutonium Isotopic Composition," presented at the American Nuclear Society Fifth International Conference on Facility Operations -- Safeguards Interface, Jackson Hole, Wyoming, September 24-29, 1995, Los Alamos National Laboratory document LA-UR-95-3326.

12. T. E. Sampson, T. A. Kelley, T. L. Cremers, T. R. Konkel, and R. J. Friar, "PC/FRAM: New Capabilities for the Gamma-ray Spectrometry Measurement of Plutonium Isotopic Composition," presented at the American Nuclear Society Fifth International Conference on Facility Operations -- Safeguards Interface, Jackson Hole, Wyoming, September 24-29, 1995, Los Alamos National Laboratory document LA-UR95-3287.

13. Leonard W. Gray, "Fissile Materials Disposition Program, Alternative Technical Summary Report: Ceramic Can-in-Canister Variant," Lawrence Livermore National Laboratory, UCRL-ID-122661, L-20219-1, August 26, 1996. 
14. Leonard W. Gray, "Fissile Materials Disposition Program, Alternative Technical Summary Report: Vitrification Can-in-Canister Variant," Lawrence Livermore National Laboratory, UCRL-ID-122659, L-20216-1, August 26, 1996.

J. E. Stewart, C. R. Hatcher, L. L. Pollat, W. C. Harker, S. Abeynaike, S. Tsalas, S. Synetos, M. Swinhoe, S. Baumann, E. Haas, K. Kohl, L. Bevaart, K. Chitumbo, P. Karasuddhi, J. King, and R. Olsen, "Development of an Integrated, Unattended Assay System for LWR-MOX Fuel Pellet Trays," Nucl. Matl. Mgt. XXIII, 842, (1994).

15. H. O. Menlove, J. A. Howell, C. A. Rodriguez, G. W. Eccleston, D.

Beddingfield, J. E. Smith, C. W. Baumgart, "Integration of Video and Radiation Analysis Data," Nucl. Matl. Mgt. XXIII, 834, (1994).

16. H. O. Menlove, M. C. Miller, T. Ohtani, M. Seya, and S. Takahashi, "Safeguards Instrumentation for Continuous, Unattended Monitoring in Plutonium Fuel Fabrication Plants," Los Alamos National Laboratory, LA-UR-93-1860.

17. J. E. Stewart, C. R. Hatcher, L. L. Pollat, W. C. Harker, S. Abeynaike, S. Tsalas, S. Synetos, M. Swinhoe, S. Baumann, E. Haas, K. Kohl, L. Bevaart, K. Chitumbo, P. Karasuddhi, J. King, and R. Olsen, "Development of an Integrated, Unattended Assay System for LWR-MOX Fuel Pellet Trays,” Nucl. Matl. Mgt. XXIII, 842, (1994).

18. D. G. Langner, J. G. Fleissner, J. B. Franco, V. Fotin, J. Xiao, and R. Lemaire, "The Performance of the 30-Gallon-Drum Neutron Multiplicity Counter at Tocky Flats Environmental Technology Site," Los Alamos National Laboratory, LA-UR-96-2569.

19. J. E. Stewart, M. S. Krick, J. Xiao, R. J. LeMaire, V. Fotin, L. McRae, D. Scott, and G. Westsik, "Assay of Scrap Plutonium Oxide by Thermal neutron Multiplicity Counting for IAEA Verification of Excess Materials from Nuclear Weapons Production," Los Alamos National Laboratory, LA-UR-96-2515.

20. Proceedings, 5th Nondestructive Assay and Nondestructive Examination Waste Characterization Conference, Salt Lake City, Utah, January 14-16, 1997, CONF-970126. 